Revista de Economia Política, vol. 29, $n^{\circ} 3$ (115), pp. 254-255, julho-setembro/2009

\title{
Réplica ao Comentário de Rodolfo Hoffmann
}

MARCOS A. M. LIMA MARCELO RESENDE*

O prof. Hoffmann levantou alguns pontos a respeito de artigo nosso recentemente publicado [Lima e Resende (2008)].

Em primeiro lugar vale ressaltar que o artigo não pretendeu propor uma medida direta de desigualdade de distribuição de renda. Essa deve ser avaliada segundo diferentes medidas que considerem mais diretamente uma variável de renda e nesse sentido notabiliza-se o índice de Theil que de resto já fora resenhado pelo autor [Hoffmann $(1991,1998)]$. Neste artigo considera-se uma generalização do conhecido índice de entropia de Theil, que é uma medida de informação esperada, no contexto de fluxos financeiros entre estados. A ideia é que, se bancos captam em uma dada localidade mas acabam aplicando estes mesmos recursos em outra, poder-se-ia identificar um fator a mais por trás da desigualdade regional e o índice forneceria uma medida sintética desse efeito.

O índice de informação esperada de Theil (1967) consiste numa generalização do índice de entropia de Theil, e compara as probabilidades a priori $\left(\mathrm{x}_{\mathrm{i}}\right)$ e a posteriori $\left(\mathrm{y}_{\mathrm{i}}\right)$ de um dado evento. A expressão deste índice é a seguinte:

$$
T=\sum_{i=1}^{n} y_{i} \ln \frac{y_{i}}{x_{i}}
$$

Em seu texto de 1998, Hoffmann, assim como Theil (1967), demonstra que este índice deve assumir valores não-negativos $(T \geq 0)$. Em seus comentários acerca de Lima e Resende (2008), Hoffmann questiona como valores negativos foram obtidos para o RFI (Regional Financial Inequality) que é baseado no índice proposto por Theil.

É importante salientar que estes valores foram obtidos por conta de uma re-

\footnotetext{
* Faculdade de Economia e Finanças, IBMEC-Rio de Janeiro. E-mail: mamdl@uol.com.br; Instituto de Economia da Universidade Federal do Rio de Janeiro:. E-mail mresende@ie-ufrj.br.
} 
definição nas variáveis $x_{i}$ e $y_{i}$ utilizadas pelos autores. As probabilidades a priori foram calculadas com base nos depósitos realizados em cada estado e as probabilidades a posteriori são relacionadas às aplicações feitas pelos bancos nos mesmos estados.

Para a construção das variáveis $x_{i}$ por exemplo, foi adotado o seguinte procedimento:

(i) Foi calculada a participação média de mercado nos depósitos para cada estado, utilizando-se uma média ponderada, pelo ativo total, das participações de depósitos de cada um dos nove bancos constantes em nossa amostra. Com isso foi obtida uma participação média (de um banco representativo) de depósitos em cada estado, para cada período;

(ii) Procedimento análogo foi considerado para as operações de crédito ao se considerar a participação média em cada estado.

O uso destes procedimentos para o cálculo da proporção de depósitos de um banco representativo em cada estado foi baseado na necessidade de se eliminar, em parte, o efeito da grande assimetria entre os tamanhos dos bancos entre os estados. Assim evitamos uma aplicação direta da expressão (1) em termos de agregados por estado. Porém, ao se adotar este procedimento, a soma dos valores das variáveis $x_{i}$ e $y_{i}$ não necessitam igualar 1 . Por esta razão é possível que as parcelas positivas $\left(y_{i}\right.$ $\left.>x_{i}\right)$ sejam dominadas pelas negativas $\left(x_{i}>y_{i}\right)$ no cálculo do RFI, o que poderia levar a valores negativos para o índice. Portanto, quando o RFI assume valor negativo, pode-se interpretar que o comportamento dos bancos do país, em maior intensidade, está captando recursos em muitos estados e os repassando para poucas localidades.

Cabe considerar que se poderia ter optado por calcular $\mathrm{x}_{\mathrm{i}}$ e $\mathrm{y}_{\mathrm{i}}$ como as proporções de depósitos em cada estado no total do país e, desta forma, usar diretamente o índice de informação esperada do Theil. Porém, ao fazer isso, perderiam parte importante da informação disponível que consistia na assimetria entre o comportamento de cada banco em cada estado distinto.

\section{REFERÊNCIAS BIBLIOGRÁFICAS}

HOFFMANN, R. (1991), O índice de desigualdade de Theil-Atkinson, Revista de Econometria, 11 (2), 143-160

HOFFMANN, R. (1998) Distribuição de renda: medida de desigualdade e pobreza. Editora da Universidade de São Paulo.

LIMA, M. e RESENDE, M. (2008) Banking and regional inequality in Brazil: na empirical note. Revista de Economia Politica 28 (4): 669-677.

THEIL, H. (1967) Economics and information theory. North-Holland. 